\title{
Educational Technology, Language and Technical Communication (ETLTC2020): Connecting the Dots
}

\author{
Debopriyo Roy \\ The University of Aizu, Dept. of Computer Science and Engineering, Japan
}

\begin{abstract}
This preface is an attempt to highlight how ETLTC2020 took an interdisciplinary approach to understand different research topics in the fields of educational technology, language and technical communication, and special topics in computer science, biomedical engineering and smart cities. This was a forum to explore how these different topics have different objectives and goals but how the researchers could collaborate and network towards more interdisciplinary research in these different areas of applied linguistics. Importantly, this conference was also an opportunity for student-student collaboration preparing them with project management and intercultural communication skills for the future workplace.
\end{abstract}

\section{The Conference Focus}

The ETLTC 2020 conference theme - Education Technology, Language, and Technical Communication was a collaboration between the use of technology in global education and the language that communicates such use to improve both education quality and customer satisfaction worldwide - was an opportunity to create synergy between educators and industry professionals across a wide spectrum of applications.

The conference's three cross-cutting themes were designed to help unpack the interrelations of quality education, use of technology for academic and industrial learning, and the technical communication that will help people understand the details of the use of such technology through the lenses of linguists and technical communicators, consumers of technology, customers who handle e-commerce technologies and interfaces that lead to learning; teachers including corporate trainers; education specialists, school and corporate leadership, and school and corporate governance.

ETLTC's community of educational researchers, policymakers, and practitioners increasingly recognize that educational and industrial challenges in the use of technology, language and communication are getting increasingly complex, dynamic and multidimensional. ETLTC was, therefore, an attempt to create a platform for exchange, learning, and collaboration between professionals who are working directly in the industry or in close association with it, and traditional faculty and students who work with different educational technologies in daily life. This platform also allowed the attendees to understand how to bridge the gap between what we teach in our classes, and how useful it is in real life industry (transfer skills).

\section{The Fields of Research: Exploring the Topics with Opportunities for Interdisciplinary Research}

Clearly, the overarching theme or question that binds educational or instructional technology, technical communication and language sciences, is how to design instructions in a way such that the design and use of language and/or the technology in combination, creates a channel, communicates a message or develop instructions for students, customers, vendors, clients etc. towards achieving a goal. When our papers for the conference talked about innovative approaches to teaching technical communication, it was mostly about the use of instructional technology or other educational software to foster technical communication pedagogy both for academic or industry [1]. Similarly, many of the languagerelated papers submitted for the conference focused on pronunciation research or language testing and acquisition but with the sole purpose of explaining or involving the use of an educational technology for the purpose of language learning, teaching and use in academic or commercial situations.

Educational technology or instructional technology is a systematic application and a disciplined approach to using relevant technological processes and resources in teaching with the ultimate goal of improving student performance and learning [2]. The use of technological processes and resources must be relevant to the curriculum goals and milestones, and consistent with the needs of the institution and the community at large. The need and demand to engage with technology on a daily basis both in and outside of the classroom is like never before. Technology is part of their lifestyle and the time spent with smartphones and tablets, YouTube etc. is tremendous, making learning more fun and accessible for today's students. Now, teachers are demanding it too. Technology is making the engagement with students more 
diversified and time-independent, providing students with the much-needed flexibility both in terms of time and engagement patterns. Most importantly, technology is probably enriching the learning experience, and in this digital age such accessibility is becoming the new normal. However, that does not mean technology can replace teachers, and the argument is valid even with the onset of AI. Technology is there to complement human teaching, not replacing it. However, a big question to answer is does technology improve education? Some scholars will differentiate between enriching the learning experience and improving the learning itself. However, there could be strong reasoning to suggest that both experience and learning can happen simultaneously. When teachers use technology effectively, it will keep the students engaged in the learning process. Teachers need to pick the right tools for specific tasks, tests and goals. The flipped classroom model, and optimization of the blended learning format geared toward student needs could be a huge advantage, and added to that the flexible pace of learning, and collaboration in online teams should make both the learning and the experience better suited to student needs [3].

Another topic that is increasingly being researched in applied linguistics is technical communication. The academic community has been researching technical communication for a long time now, but much of that research is quite a bit independent and set apart from how technical communication is looked at, and used in the industry. Fortunately, academic research has addressed that point [4].

Technical communication in the industry is more into managing documentation processes including increased volumes, complexity and deliverables; delivering more languages to support more markets; reducing costs and shortening delivery timeframes; maintaining the highest quality, clarity and consistency to meet increased regulatory, legal and safety requirements in the 'physical' world [5]. The TC discussion in this conference shifted from the traditional research in academia and more into how digital transformation is creating challenges for traditional systems and organizational functioning to unify the customer journey. The discussion went further into exploring if there could be opportunities to reposition technical communication as a strategic activity unifying a company's conversation with the customer about products and services? The idea was to explore academia-industry relationships and partnerships and related perspectives [6].

Another interesting topic that we considered as a major theme for ETLTC2020 was the gradual shift from computer assisted language learning towards mobile assisted language learning [7], and should language teachers redefine the language context for a world in which language use is now a means to an end, where international people are using English alongside their own language in order to achieve real life purpose online. Many of the presentations in this conference also focused on different language learning, testing and administrative tools, including language learning apps, discussions on AI and big data that could have both academic, industrial and societal applications.

Moreover, as part of this conference we wanted to open up discussions on special topics in computer science, biomedical engineering and smart cities as tracks to have a more comprehensive outlook on a wide-ranging topic in a way such that a diverse multi-disciplinary approach to teaching and research could be promoted, and more ideas and approaches discussed. Another important aspect of the ETLTC2020 was the semester-long collaboration between the students of the University of Aizu and the HSKA, Germany which is now in its second year and resulted in a collaborative project on smart cities and technical communication. The idea of the project was to promote intercultural exposure and project-based collaboration and language learning. So, this conference was designed to be a forum for networking where participants from diverse faculty with a missing link came together, and explored how they could communicate and collaborate for research and other projects in near future. Further, this conference clearly had a strong focus on student-student collaboration preparing them for collaborative professional projects in the industry by raising their project management and intercultural communication skills [8].

\section{ETLTC2020 Attendance}

The event was held in collaboration with the international symposium on spatial media (ISSM2020). ETLTC2020 had about 90-100 participants in total for the 5-day event. For the academic presentations and attendance, the following countries and universities were represented.

\begin{tabular}{|c|c|}
\hline Countries Represented & Japanese Universities \\
\hline $\begin{array}{ll}\text { - } & \text { Germany (a } 14-\text { member team from academia \& industry) } \\
\text { - } & \text { Greece } \\
\text { - } & \text { Hong Kong } \\
\text { - } & \text { Indonesia } \\
\text { - } & \text { Ecuador } \\
\text { - } & \text { USA } \\
\text { - } & \text { Nepal } \\
\text { - } & \text { Mexico } \\
\text { - } & \text { Russia } \\
\text { - } & \text { Taiwan }\end{array}$ & $\begin{array}{ll}\text { - } & \text { Waseda Univ. } \\
\text { - } & \text { Namamoto Univ. } \\
\text { - } & \text { University of Kitakyushu } \\
\text { - } & \text { Kochi University of Technology } \\
\text { - } & \text { Osaka University } \\
\text { - } & \text { Rikkyo University }\end{array}$ \\
\hline
\end{tabular}




\section{Conference Presentation}

The conference included the following sessions:

\section{Individual Paper Presentation:}

Paper sessions were 90 minutes in length and included 5-6 papers, in general and included many research papers on educational technology, language, technical communication and topics in computer science.

\section{Poster:}

Poster sessions combined the graphicsdisplay of technical communication research materials with the opportunity for individualized, informal discussion of a project in research, policy and/or practice. Individual presenters set up displays in a large area with other presenters. Posters were set up to be during the final day of the conference.

\section{Workshop:}

Workshops (90 minutes long) offered a forum for discussion of a broad range of emerging and specialized topics of interest to the ETLTC community. Two workshops happened between the students of University of Aizu and HSKA, Germany. These sessions were interactive and more informal than paper sessions and involved extended discussion, group brainstorming sessions, mini-tutorials around key ideas, and proof-of-concept demonstration sessions.

\section{Submission Genres and Topics}

The SIX major genres for paper submission were as follows:

A. Computer Assisted Language Learning

B. Task-based Language Learning

C. Educational Technology in Academia and Industry

D. Information Design and eLearning

E. Technical Communication

F. Special Track: ICT, Design, and Planning for Smart Cities

\section{A. Computer Assisted Language Learning}

1) Language Learning Environments and CALL

- Designing and implementing contextualized technology-enhanced language learning environments

- Local versus global CALL environments

- Blended learning and hybrid courses

- E-learning systems

- Flipped classes

- Assessment \& evaluation of CALL environments

- Task-based CALL in online systems

- Computer-Supported Collaborative Language Learning (CSCLL)

- Network-based language teaching (NBLT)

- Effective feedback strategies in online systems

- Productivity suites

- Project-Based Learning

- Virtual reality

- Websites for language practice

- Course Management Systems

\section{2) Ubiquitous Language Learning}

- The use of mobile technologies, such as tablets, iPads, smartphones, etc., to provide flexibility and access to language learning opportunities

- Best practices in the use of technology for learning a language anytime, anywhere, and with any device

- Methodological implications for mobile technology content development

- Developing language materials for ubiquitous learning

- Podcasting

- Apps for language learning

- Modes of delivery

- Mobile Learning and Ubiquitous Technologies 
3) Intercultural Language Learning through ICT

- Telecollaboration and video-web conferencing

- Exploiting social networks for language learning

- Computer-supported collaborative language learning across frontiers

- Cross-cultural awareness through ICT

- The use of social networking technologies by language teachers and learners to share expertise, knowledge, and information

- Social networking

\section{4) Worldwide Collaborative CALL}

- Open (Linked) Data and Open Content

- MOOCs for language learning

- Harmonizing theories, research, and practice

- Free/shareware/open source technology for developing language learning materials

- Working collaboratively to disseminate and adapt innovations so that they can be used by practitioners separated by location or culture

- Growing innovation through collaborations across international institutions

- Working towards worldwide collaboration for the sharing and re-use of digital language learning materials

- Design and development of applications that cross geographical, physical, psychological, and financial boundaries

- Catalyzing international cooperation for language learning

- Open Educational Resources

- Identifying priorities of particular languages, groups and/or regions, with the aim of increasing collaboration and growth

- Facilitating wider access to multilingual quality language learning worldwide

- Growing diverse online communities of language learners/teachers

5) CALL and Multidisciplinary Approach for Targeting Learners' Needs

- From needs analysis to multidisciplinary language learning materials design

- Bridging the gap between language teachers' perspectives and new language learners' needs

- Augmented reality in second language teaching and learning

- CALL for matching learners' minds

- Learners just want to have fun: technology and games for language learning

- Game-based learning strategies in technology-enhanced language learning environments

- Gamification and virtual reality

- Language learning systems for targeting specific audiences

- Corpus-aided language learning

- Semantic Web 3.0

6) Teacher Professional Development and CALL

- Integrating CALL in initial teacher education

- Integrating CALL from k-12 to tertiary education

- Teacher training in ICT for enhancing language learning

- Developing strategies for teacher education and professional development

- CALL on a small budget

- Extra-curricular study

7) $\underline{I C A L L}$

- ICALL and ITS systems for e-learning platforms

- Natural Language Processing in language learning

8) Learner's Autonomy and CALL

- Supporting the development of language learners' autonomy

- Motivation, guidance, and accountability in language learning without the teacher present 
- Self-efficacy and learner autonomy, self-regulated language learning

- Learner behavior

\section{9) CALL Framework}

- Developing theoretical frameworks, models, principles, and guidelines for the development of CALL

- Changes to the use and application of CALL terminology

- Pedagogy for developing CALL

\section{0) CALL Research}

- Current and perceived future CALL trends, gaps, and research needs

- Developing qualitative and quantitative studies (methods, techniques, tools, etc.)

- Corpora \& Databases

\section{1) Evaluation and assessment}

- Assessing language learning achievements (knowledge, skills, attitudes, motivation, satisfaction)

- Criteria for evaluating the effectiveness of language learning software systems

- Assessment strategies in b-learning and e-learning environments

- Computer-based languages tests

\section{2) CALL for Minority Languages}

- Safeguarding endangered and indigenous languages through technology

- CALL for Teaching Less commonly taught languages

\section{3) CALL and Government Priorities for Language Learning}

- Evolving national and international government priorities that impact upon the overall use ofCALL

- Common international language standards for curriculum and syllabus development

\section{4) CALL Materials Design}

- Listening, Speaking and Pronunciation

- Reading

- Writing

- Grammar

- Curriculum development

- Podcasting

- Video

- Sustainability of resources

- Low-cost devices

- Pedagogy for developing CALL materials

\section{B. Task-based Language Learning}

- Tasks in SLA

- Tasks in language education

- Theoretical perspectives on TBLT

- Sociocultural aspects of TBLT

- Task features, complexity, design

- TBLT methodology

- TBLT implementation and innovations

- Technology-mediated TBLT

- Tasks and the role of the learner

- The role of the teacher and TBLT-based teacher education

- TBLT in contexts

- Needs analysis in TBLT

- Task-based assessment

- Evaluating task-based instruction, materials, and programs 


\section{Educational Technology in Academia and Industry}

1. Education in Context

- Education in the Network Society

- Educational Games

- Social Media in Education

\section{Education as Professional Field}

- Teacher Education

- Teachers' Professional Development

- Teachers' Workload

- Teacher Support for Grading, Time Tabling, Grading, Learning Tools, and Online Learning Software

- Teachers' learning in Communities of Practice

- Web-based Communities for Teacher Support

\section{Curricular Evolution}

- Problem-based Learning

- Critical Thinking Skills

- Creativity Skills

- Learning Citizenship

- Global Education with Technology

- Media Literacy / -Pedagogy

- Multicultural Education with Technology

\section{Integrating Educational Technologies}

- Social Media and Social Networking

- The Semantic Web 3.0

- Podcasting for Broadcasting Video Lectures

- Podcasting feedback to students

- Wiki and blogs in Higher Education

- Mobile, Virtual and Vicarious Learning

- Simulations and Modeling

\section{International Higher Education}

- Web-based, Mobile, Virtual Presence and Social Media to Overcome Student Mobility

- Blended Learning and Student Assessment at a Distance

- Student Mobility and Distance Education

\section{Information Design and eLearning}

- E-Learning Evaluation

- E-Learning Tools and Systems

- E-Learning Content Development

- Electronic Publishing Tools E-Learning

- Engaging Students with the World Digital and Global Discovery Online Virtual Universities, Classrooms, and Laboratories

- Developing and Organizational e-Learning Strategy

- Developing, Integrating, and Delivering E-Learning

- Solutions Digital Libraries for E-Learning

- Distance Education

- Distance Learning

- Methods and Procedures for the Global Classroom

- Industry-University Partnering Infrastructure of E-Learning Environments Interactive E-Learning Systems 
- Knowledge Management in E-Learning

- Quality Management and Assessment in E-Learning

\section{E. Technical Communication}

- Technical Communication

- Structured authoring and information modeling

- Semantic modeling and ontology applications

- Process integration and modeling of products and information

- AI applications in technical communication Specific concepts of intelligent content

- Dynamic and interactive content delivery

- IoT and Industry 4.0 concepts for technical information

- Content analytics and metrics

- Search and Retrieval scenarios of technical information

- Content generation

- User-generated content

- Elimination of information silos

- Technical videos

- Augmented and virtual reality

- Mobile documentation

- Agile project management

- Cross-cultural and Global Communication

- Electronic Forums and Meetings

- Usability and Usability Testing

- Visual Communication

- Writing Processes, Thinking Processes

- Workplace Culture

\section{F. Social Communication related to ICT, Design, Smart City and Society}

- Design Thinking and Planning

- Smart Parking

- Car sharing services

- Traffic and public transport

- Clean energy

- Smart building

- Waste disposal

- Environmental protection

- Citizen participation

- Digitization of governance

- Urban planning

- Education

- Business ecosystem

- 4G LTE

- Internet Speed

- Wifi Hotspots

- Smartphone penetration

- Living standard

- Healthcare Electronics

- Smart Healthcare 


\title{
6. Submission Topics \& Scope
}

All submission types were blind refereed. The evaluators reviewed all submissions without the names of the authors and presenters.

\subsection{Submission Guidelines}

Papers were no more than 10 pages maximum (including abstract, references, appendix, etc.).

\section{Paper Length:}

Full Papers: Between 6-10 pages

Short Papers: Between 3-4 pages

Extended Abstract Papers: 1-2 Pages (around 600-800 words including references)

\author{
Paper Content Type: \\ Full Research Paper \\ Tutorial \\ Teaching Experience \\ Project Experience \\ Software Review \\ Teaching or Research Position Paper
}

\subsection{Evaluation of proposals}

Proposals were blind reviewed in the EDAS system and evaluated by members of the ETLTC2020 Program Committee. Proposals were judged for their contribution to educational technology theory and application and technical communication policy, research, and/or practice, the quality of explanation pertaining to the aims of the presentation, theoretical perspectives, methods of inquiry and analysis, strength of results and conclusions, and connections to the conference theme.

- For long papers, we looked into completed research that clearly highlights how a study is conducted, the findings, the discussion of the results and its implications.

- For short papers, we looked for studies in preliminary stages, but which clearly puts a detailed framework explaining the next course of action or expected results.

- Extended Abstracts provided the opportunity for the author to share an initial work-in-progress report or an idea that could be tested through a paper and accompanying talks at the conference. An experience report is a reflection of their own industry experiences (e.g. challenges they have seen, what they tried and approaches they have taken, what worked and what didn't work).

- A Research Paper was complete with an introduction, data, and analysis of data, discussion and implications.

- A Tutorial clearly explained how software or a product (e.g., educational technology) could be used towards certain specific goals.

- Teaching Experience papers clearly highlighted the course module, how it's designed, the pedagogical strategies, classroom experience (with some data) and implications for teaching.

- The Project Experience papers clearly highlighted how the project was conceptualized, reasons for using the approach, people and resources involved, what was aimed and achieved, the learning that happened, and its overall implications.

- The Software/Hardware Review papers clearly explained the purpose of the software/hardware, the domain of application, the design of the interface, how users are expected to use it, and how it's actually used, the learning that happens, the user experience and the reliability and trustworthiness of the product in the market, and/or in the specific community of use.

- The Teaching or Research Position papers explained the idea behind an approach, whether such use or application is valid and reasonable, what are the theories backing such application, or any contrary theoretical evidence to suggest the failure of such research approach, or pedagogical strategy.

\section{Publication}

ETLTC2020 published an abstract proceeding with ISSN number. This proceeding included both the abstract and extended abstracts (up to 2 pages long) which were not submitted through the EDAS system. The $1^{\text {st }}$ drafts or the abstracts for all the short paper (four pages long) and long paper (up to 10 pages long) submissions were peer-reviewed and submitted for publication with SHS Web of Conferences. However, among the list of all final short and long paper 
submissions, four best papers were selected, and those papers were forwarded for an additional round of review before being considered for publication in a special issue of International Journal of Computer Assisted Language Learning and Teaching (IJCALLT). IJCALLT is a major journal in the field of technology assisted language learning and indexed in Scopus and other major indices.

\section{The Keynote Speakers}

ETLTC2020 had 11 keynote speakers from industry and academia.

\section{Prof. Wolfgang Ziegler}

Information \& Content Management

The Karlsruhe University of Applied Sciences, Germany

\section{Prof. Glenn Stockwell}

Professor \& Associate Dean, Dept. of Law

Waseda University, Japan

\section{Prof. Martin Schober}

Professor of Internet \& Media Technology

Karlsruhe University of Applied Sciences, Germany

Prof. Gordon Bateson

E-learning Laboratory, Department of Core Studies

The Kochi University of Technology, Japan

\section{Prof. Kiyomi Okamoto}

Center for Fundamental Education

Faculty of Environmental Engineering

The University of Kitakyushu, Japan

\section{Prof. John Blake}

Center for Language Research

The University of Aizu, Japan

\section{Prof. Satoshi Kuroda}

Councilor, Chairman of the Planning Committee of Public Affairs, JTCA

Center for the Study of Co* Design

Osaka University, Japan

\section{Prof. Ana Cristina Garcia Luna Romero}

Department of Architecture

The University of Monterrey, Mexico

\section{Mr. Christian Deschner}

Siemens Healthcare GmbH

Technology \& Innovation Lifecycle Excellence

Core Tool Harmonization, Germany

\section{Dr. Sven Leukert}

VP, Knowledge Management at SAP

Mannheim Area, Germany

Prof. Hiram Alejandro Cantu Campos

Director, Biomedical Engineering

Academic Program

The University of Monterrey, Mexico 


\section{The Organizing Committee}

The organizing committee was chosen from a wide range of institutions, partner universities and from both academia and industry.

\section{Honorary Chairs}

Ryuichi Oka - Univ. of Aizu, JP

Toshiaki Miyazaki - Univ. of Aizu, JP

\section{General Chairs}

Debopriyo Roy - Univ. of Aizu, JP

\section{PC Chairs}

Debopriyo Roy - Univ. of Aizu, JP

John Blake - Univ. of Aizu, JP

\section{PC Co-Chairs}

Takako Yasuta - Fukushima Medical Univ. Japan

\section{Special Session Chair}

Gordon Bateson - Kochi Univ. of Technology, JP

\section{Publicity Support}

Wolfgang Ziegler - Karlsruhe University of Applied Sciences, Germany

Motoo Akiyama - Japan Technical Communicators Association, JP

Ana Cristina Garcia Luna Romero - University of Monterrey, Mexico

Hiram Alejandro Cantu Campos - University of Monterrey, Mexico

\section{Publication Chair}

John Blake - Univ. of Aizu, JP

\section{Publication Advisors}

Glen Stockwell - Waseda University, Japan

\section{Local Organizing Chairs}

Mohamed Hamada - Univ. of Aizu, JP

Rentaro Yoshioka - Univ. of Aizu, JP

\section{Advisory Committee}

Wolfgang Ziegler - Karlsruhe University of Applied Sciences, Germany

Thilak Hapugahage Chaminda - Lanka Nippon Biztech Institute (LNBTI), Sri Lanka

Neil Johnson - The Univ. of Sunderland, United Kingdom

Kazunori Nozawa - Ritsumeikan Univ, JP

Kiyomi Okamoto - The Univ. of Kitakyushu, JP

Bradley Irwin - Nihon University, JP

Anubhav Bhatia - VP Engineering- SAP Labs, Member-Forbes Technical Council, IEEE Senior Member John Brine - Research Associate, Dept. of Computer Science, Univ. of Waikato, Hamilton, New Zealand

\section{Registration Chairs}

Debopriyo Roy - Univ. of Aizu, JP

John Blake - Univ. of Aizu, JP

\section{Steering Committee}

Ben Abderazek - Univ. of Aizu, JP

Michael Cohen - Univ. of Aizu, JP

Shigaku Tei - Univ. of Aizu, JP 


\section{Sponsors}

Major Sponsors - The University of Aizu, ACM Chapter on eLearning and Technical Communication, and Karlsruhe University of Applied Sciences, Germany.

Major Partners - University of Monterrey, Mexico, and Japan Technical Communicators Association

\section{Project Partners of the Japanese-German Academic Cooperation Project -}

DOCUFY is a leading software manufacturer for multi-level documentation systems and is the first provider of Multi-Level Documentation. Besides its software products, DOCUFY also offers consulting and development services and professional support. The ISO 9001:2015 certified company is based in Bamberg and employs around 120 people. The software specialist also markets its multilingual software worldwide via a network of partners. Since 1 May 2017, DOCUFY has been a Heidelberg Group Company.

SCHEMA develops component content management and content delivery solutions for authoring departments creating product-related content. SCHEMA software supports businesses in describing complex products and in publishing and distributing content. The component content management system SCHEMA ST4 is one of the most frequently used systems for the modularised creation of documentation, package inserts, and marketing documentation. The system covers all areas of content creation in technical writing - from authoring assistance during input to the finished layout for printed catalogs. The SCHEMA Content Delivery Server provides businesses with a standard solution to automatically share intelligent information with end users.

Expert Communication Systems GmbH, a company domiciled in Haar near Munich, is the maker of the browser based XML editing system "Smart Media Creator". Thanks to modern technology and structures, SMC excels with high efficiency and usability and can be run in many areas of technical documentation and technical marketing. Sample fields of application are: Manuals / instructions, catalogs / data sheet, software documentation / online help, web content and mobile devices, elearning or marketing media. Expert Communication Systems offers a wide range of services around the installation and application of the editing system, thereby contributing to a fast and safe ROI of projects in different dimensions.

ONTOLIS is a web-based software family for general knowledge management. Using the powers of ontologies, ONTOLIS enables you to depict all relations and coherences of your desired domain. Since ONTOLIS is highly configurable, it can easily be optimized for the customer's needs and use cases. The team behind ONTOLIS has 20 years of experience in DLM. This has left its mark: ONTOLIS offers innovative solutions for content management and delivery, which makes it the first CMDS. An essential part of this is QIRA - ONTOLIS' own language for querying, transformation and reasoning of ontology data. ONTOLIS delivers intelligence for your data.

i-views - The company intelligent views from Darmstadt, Germany was founded in 1997 is the vendor of the semantic graph database i-views and is a leading provider of semantic-based information portals. The content delivery portal iv-content is based on our core engine and brings the full power of semantic web technologies to the area of content delivery portals. ivscontent supports a large variety of input formats for technical documents and offers a full metadata management system for the automatic and manual annotation of content. Intelligent searches, personalized access, and offline apps are further key features of the solution.

\section{References}

[1]. Woolever, K. R. (2005). Innovative approaches to teaching technical communication. Technical Communication, 52(1), 73-75.

[2]. Januszewski, A., \& Molenda, M. (Eds.). (2013). Educational technology: A definition with commentary. Routledge.

[3]. Means, B. (2010). Technology and education change: Focus on student learning. Journal of research on technology in education, 42(3), 285-307.

[4]. Whiteside, A. L. (2003). The skills that technical communicators need: An investigation of technical communication graduates, managers, and curricula. Journal of technical writing and communication, 33(4), 303-318.

[5]. Ballard, D. (2017). Technical Communication - A profession in transformation in the digital age or simply business as usual? LinkedIn.com (June 14). https://www.linkedin.com/pulse/technical-communication-profession-transformationdigital-ballard-1/

[6]. Bridgeford, T., \& Amant, K. S. (2017). Academy-industry relationships and partnerships: Perspectives for technical communicators. Routledge.

[7]. Jarvis, H., \& Achilleos, M. (2013). From Computer Assisted Language Learning (CALL) to Mobile Assisted Language Use (MALU). Tesl-ej, 16(4), n4.

[8]. Roy, D., \& Ziegler, W. (2019, July). Logistics and Challenges of an Intercultural Technical Communication Collaborative Project between Two Japanese and German Universities. In 2019 IEEE International Professional Communication Conference (ProComm) (pp. 18-24). IEEE. 